\title{
Una mirada indisciplinada hacia la educación por el arte
}

Ramón Oscar Cabrera Salort

Universidad de La Habana

\begin{abstract}
"Pienso que el artista que no se preocupa por el efecto de su arte en el público se limita a hacer auto-terapia, y que el educador que no es creativo no debiera enseñar. El buen artista y el buen educador en realidad están en la misma profesión, solamente utilizando medios distintos."

Luis Camnitzer.
\end{abstract}

\section{Abstract}

Through a theoretical route experienced in academic land about the art and refers to the specific contexts of the graduate at the Higher Institute of Art (Havana, Cuba), settled liminal ideas unfold in paradigm changes of knowing the world and in recognition of porous boundaries between the sciences and the arts and modalities of inquiry, which becomes an indisciplinar look.

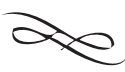

\section{Iniciar con una anécdota}

Hace cerca de un lustro atrás tuve que desempeñar la tarea de oponente a una tesis doctoral en Ciencias Pedagógicas alrededor del tema de la enseñanza de la Literatura desde el canon literario. Tesis bien escrita e inobjetable desde el supuesto que partía, mostraba a mi entender como evidencia todo aquello de lo cual no hacer partir nunca la enseñanza de una materia, si se quería que fuese un asunto del campo de las artes. Esto significaba que el estudio de la obra literaria debía hacerse partir no del modelo que llegó a ser, sino del cambio, de la ruptura que representó ante lo canónico de su tiempo. Parodiando un pensamiento de Sábato sería mostrar al Cervantes que escribió el Quijote, no como resultado de una obra académica, envejecida, escolar, antológica, sino como el 
escrito de un aventurero, lleno de vida y despreocupado de la vida (Sábato, 2011): como una obra viva que derribó los castillos habituados de las novelas de caballerías.

Podemos planear sobre hitos de la historia del arte e infinitos podrían ser los ejemplos, en artistas, en géneros, en nuevos territorios de la visualidad, que demostrarían que el modo de enseñarlos como arte en las aulas es reviviendo la experiencia compartida entre docentes y discentes, con todo lo que tenían de innovación, de cambio, de ruptura, de indisciplina y no lo que han llegado a ser como modelos, como pautas, contrario todo ello de lo que en su contexto original fueran.

\section{Un repaso histórico}

Cuando con motivo de la XI Bienal de La Habana, en la primavera del 2011, desarrollamos un grupo de profesores y estudiantes un panel que recogía los principales argumento desde los cuales habíamos vivido la docencia de un diplomado recién concluido, perteneciente a una proyectada Maestría en Producción Simbólica, no dudamos en titularle "La construcción de una mirada indisciplinada". Cuando proyectamos el ámbito temático que presidiría nuestro actual Seminario/Taller "Mediaciones, Interculturalidad y Educación por el Arte en América Latina" no dudé tampoco con el título para mi conferencia "Una mirada indisciplinada hacia la educación por el arte".

Siempre he mantenido el criterio de que el arte al cual debe remitirse un educador es el de su momento, el de su actualidad, ya que la escuela siempre ha de estar a la altura de su tiempo para evitar descentrarse, hecho al que alude muy certeramente Jesús Martín Barbero al referir cómo se manifiesta la circulación de los saberes por fuera de la escuela y de los libros - a lo cual denomina descentramiento-, y cómo se da a la par lo que califica como la difuminación de las fronteras que separan los conocimientos académicos del saber común - para lo cual emplea el término diseminación (Martín Barbero, 2010). Quede, entonces, la mirada que echo sobre todo, insubordinada, transgresora. Pero veamos primero razones históricas que encuentro hoy superadas.

Quizá valga la pena aludir de un modo bocetado a cómo el auge de nuevas disciplinas y prácticas discursivas en el siglo XIX, estuvo parejamente acompañado con la institucionalización de la escolaridad y la fundación de sistemas escolares en todos los países. Disciplinas recientemente desgajadas en aquel siglo del discurso filosófico como la Pedagogía, la Psicología, la Sociología, la Antropología y otras nacieron a la sombra de los grandes avances en el campo de las Ciencias Naturales. Esto no tardó en permear el discurso de esas y otras recientes disciplinas de estudio de la época como la Historia del arte. Así es como Hipólito Taine explicaba y clasificaba las formas artísticas como una "especie de botánica aplicada a las obras humanas" y, de igual modo, pretendía tratar a los sentimientos y las ideas como se hace con las funciones y los organismos y considerar la vida social como un laboratorio (Taine, 1994).

Para un intelectual del siglo XIX como el cubano Manuel Sanguily la crítica será 
científica o no es crítica, afirmaría categórico en un artículo suyo de la época (Sanguily, 1988). Y con esto se muestra ese impulso cientificista que dominaba todos los órdenes. En el arte se verá claramente en el Impresionismo y en la novelística, donde los personajes al impulso, entre otras, de las razones que exponía Taine quedaban encadenados fatídicamente al ambiente y la herencia. De los impresionistas dirá José Martí, para incisivo destacar los nuevos tiempos, que vienen al arte en una época sin altares, ni tienen fe en lo que no ven, ni padecen el dolor de haberla perdido, con lo cual destaca ese sentido de objetividad positiva (Martí, 1985, 115).

El evolucionismo de Spencer, la sociología de Comte repudian las especulaciones a favor de los hechos y las experiencias positivas. Así la Psicología naciente reclamaba la validez de su existencia con idénticos procederes que los de la química y la biología. El asunto de la medición ligado a la cientificidad, a la verificabilidad y su remisión a comprobar la regularidad: la ley, se convirtió en paradigma que llega a nuestros días. Es el criterio de Wilhelm Wundt (1823-1920) con una psicología que solo admite hechos si recurren a la medición y la experimentación.

La mirada que sobre las cosas echaba el siglo XIX era optimista, veía el mundo de modo "positivo", cimentado en una idea de progreso que se desprendía de los desarrollos científicos y tecnológicos, así quedaron manifiestos en la exposiciones universales de la época. Y de esta manera se va desenvolviendo un progresivo proceso de construcción de las fronteras discursivas, alcanzado no sin rodeos, ni titubeos. Por ello, todavía a inicios el pasado siglo un pedagogo como el belga Georges Roumá sustentará su tesis del lenguaje gráfico del niño, como investigación en opción al título de doctor en Sociología, siendo esta de las primeras indagaciones sistematizadas y debidamente justificadas en imágenes de la evolución de los trazos infantiles y de su correlación con indicadores intelectuales, amén de ofrecer un exhaustivo cuadro comparativo de los principales estudios que hasta aquella época se habían realizado sobre el grafismo infantil y sus métodos: sus bondades y sus falencias (Rouma, 1919).

El movimiento de la Nueva Educación va a surgir animado de esa conciencia positiva y al abrigo del dominio de las Ciencias naturales va a tener una visión del desarrollo infantil de dimensión biogenética, con lo cual se reserva al niño toda la potencialidad de su devenir evolutivo, mas junto a esto alcanzan las artes un protagonismo nunca antes visto. Será esta la época en que cobra fuerza la triada vinculante de lo infantil, lo primitivo y la locura como mundo analógicos que rompen con la mansedumbre de las costumbres y las rutinas sociales, carentes de autenticidad y vida. Y no habrá artista de vanguardia que deje de anotar su total adhesión a tal ámbito de relaciones. Siempre será posible, no obstante, observar cómo esto se sucede en nuestra América, tanto por el modo en que se viven y se desenvuelven las artes en el continente, como por la manera en que el movimiento de la Nueva Educación encarna en él, desde una realidad de compromiso comunitario y de inserción en ámbitos populares y desfavorecidos de la sociedad, donde los elementos expresivos de las artes, encarnan en realidades escolares de innegable trascendencia, lo que años después el inglés Herbert Read teorizará en su Educación por el arte. Así las experiencias legendarias de Jesualdo, las hermanas Cosset- 
tini, Luis F. Iglesias, a las cuales podríamos sumar muchas otras que están por indagar en nuestra vasta geografía americana.

A partir de aquí arte y educación por el arte comenzarán a vivir una suerte de relación que llega a nuestros días, pero no de una manera espontánea, sino a través de una fuerte conciencia de relación que alcanza sentido de necesidad en la misma medida que el educador y los educandos trabajen para ello. No extraña, entonces, reconocer que quien escribiese uno de los texto fundacionales de educación por el arte, fuese a la vez un notable crítico del arte moderno de su tiempo: Herbert Read; ni que en consonancia con las aspiraciones de las vanguardias históricas depositara en la expresión uno de los principales cometidos del arte y de su educación. Cuando en los 60 ese momento expresivo comenzaba a enjuiciarse desde sus limitaciones y carencias para la educación, van a surgir sucesivas propuestas que quedarían coronadas con la DBAE en sus diversas variantes y que le haría decir a Ana Mae que ese enfoque del arte en la educación, desde disciplinas constituyentes como la producción, la historia, la crítica y la estética, era un modelo característico de la modernidad desde la prevalencia de lo disciplinar (Ana Mae, 2011). Pero a la par es factible reconocer que superar el enfoque del arte en la educación solo centrado en su visión de taller para hacerle espacio a las teorizaciones, no deja de correlacionarse con la etapa en que ciertos artistas de la nueva vanguardia conciben su atelier desde los silenciosos espacios de la biblioteca y las paredes de ciertas galerías dispuestas al riesgo con tales propuestas, exhiben textos escritos en vez de pinturas, la detallada planeación documental de una acción o conjunto de operaciones, más que el testimonio objetual de una escultura o un grabado, suficientes en sí mismos.

Este momento cognitivo de la enseñanza del arte es coincidente con un nuevo enfoque de los modos de cognición. De una secular tradición científica asentada en las leyes de la mecánica de Newton, con un universo del discurso de la ciencia estructurado bajo el principio de continuidad de la realidad, de continuidad del tiempo y de la historia del conocimiento, que concibe el discurso de la ciencia en relación de isomorfismo al universo en su totalidad y con un saber clasificado exhaustiva y ahistóricamente, desde la admisión de un punto de vista absoluto como lugar fundamental de observación que disuelve al sujeto, se pasa, a partir de nuevos descubrimientos de las ciencias, a reconocer que el universo categorial de la misma no es unitario, ni homogéneo y que el conocimiento y la ciencia no se construyen por expansión (Ceruti, 1998).

Y todo esto a la vez remite al reconocimiento del carácter estructuralmente inconcluso de todo sistema cognitivo, y a esa inconclusión como condición de su funcionamiento y de su identidad, lo que conlleva a un debilitamiento de los enfoques sintéticos asociados a meta-puntos de vista, de criterios, de ordenamiento, con respecto a objetos absolutos y con función normativa. De esta manera, cualquier criterio u ordenamiento supone una elección, donde integrar la subjetividad y la objetividad del enfoque propio, en la que el observador siempre porta su limitación, corresponde a una determinada matriz de conocimiento adonde queda confinada su [objetividad]. La imagen científica de hoy será la "red de modelos", nos confirman I. Priogine, E. Glaserfeld, H. Foerster, N. Luhmann, H. Maturana, entre otros (Watzlawick, 1998). Y así se reinserta al sujeto, al 
observador y su punto de vista en el tejido final del conocimiento.

El arte como forma particular de conocimiento del mundo y, en especial, el de nuestros días centrado en un observador, en un sujeto, mas no en un sujeto trascendente que construya una propuesta de mirada total, dejará de tener en la historia del arte, en las técnicas artísticas tradicionales y en el discurso histórico de la estética y sus categorías dominantes, sus fuentes primarias de remisión. En vez de ello, transitará por las más disimiles disciplinas del conocimiento ya sea de manera intuitiva o enfáticamente consciente y construirá propuestas de obrar que no siempre se adaptan a los espacios exhibitivos tradicionales del museo o la galería y que en más de una ocasión nacen y se desenvuelven en los espacios citadinos más diversos.

A continuación voy a referirme a cómo fue asumida esta visión transgresora de disciplinas tradicionales desde la docencia universitaria de posgrado en la formación artística, hecho que no hallo alejado de lo que parejamente deba suceder cuando se trata de encarar contemporáneamente el arte para todo sistema escolar, pues siempre estará vigente el principio de actualidad sobre el arte del que debemos aprender todos.

\section{Miradas para ojos inquietos}

Hace años el novelista mexicano Carlos Fuentes confesaba que había crecido en la era de la radio y que ésta implicaba diferir la vista, aplazar la visión, entre tanto la escucha hilaba la historia. Confiesa, entonces, que su imaginación surgía de sonidos y palabras. Pero, a la par, reconocía que sus hijos fueron alimentados por la dieta visual de la televisión. El estudioso francés Regis Debray cuando decide historiar la mirada reconoce un primer estadio dominado por la imagen como ídolo -ella nos mira-, la imagen como arte -ella se deja mirar- y la imagen construida, fabricada, a partir de la televisión a color, donde se acrecienta el poder de un mirar sin mirada (Debray, 1994).

Yo crecí como los hijos de Fuentes con el alimento diario de la televisión y mis hijos y mis estudiantes ya participaron, además, de los videos juegos, los nintendos y del juego infinito del mundo digital, como trato natural con las imágenes, donde todo aparece y desaparece al tacto con la nerviosa palpación del clip. Esta experiencia de cambios de imaginarios sociales y visuales resultó una de las razones que sustentó el panel $\mathrm{La}$ construcción de una mirada indisciplinada, celebrado en el ISA, Universidad de las Artes de Cuba, como parte de las actividades del Evento Teórico de la Oncena Bienal de La Habana, el pasado año. Respondía, además, a las propositivas inquietudes desgajadas del discurso simbólico de las jóvenes hornadas de artistas egresados de la Facultad de Artes Visuales, donde el tránsito hacia territorios novedosos y entreverados con las más acostumbradas maneras de hacer, se integra orgánicamente a necesidades construidas desde poéticas personalizadas que no vuelven miméticamente la cabeza hacia lo último, si no hacia razonados argumentos desde contextos propios.

El panel lo constituyeron maestros y estudiantes del Diplomado de Producción 
simbólica concluido durante el pasado curso escolar. Estuvimos reunidos, por tanto, para exponer nuestras ideas no solo sobre el desarrollo de nuestro diplomado en varias generaciones de graduados, sino como una suma integrada de miradas y experiencias alrededor de un proyecto que se quiere tenga continuidad como Maestría de Producción Visual y que se engarzaba perfectamente, a la par, con el tema general de la Bienal Prácticas artísticas e imaginarios sociales y con acuciantes problemáticas surgidas del quehacer simbólico de los mismos estudiantes.

El diplomado nacía motivado también por el creciente auge que sentíamos en la producción simbólica contemporánea, en cuanto a la naturaleza híbrida de los productos artísticos de hoy. Hibridez que se reconoce, no solo en la difícil determinación con la cual se tropieza el público ante productos que no se dejan reconocer claramente dentro de un territorio específico del arte, sino también la que se vivencia entre la producción simbólica y lo que puede pertenecer al campo indeterminado del suceder cotidiano, desde subirse a un ómnibus hasta sostener fijamente una mirada - en fin, el diálogo incesante entre la poética y la prosaica, diría Katia Mandoky. Y de lo cual pueden ofrecer testimonios directos en sus obras tanto jóvenes profesores del diplomado como sus estudiantes, todos egresados en los recientes años que inician el nuevo siglo.

Por eso primero expusimos las razones que habían dado lugar a la tónica que dominaba en el diplomado, y ellas fueron develadas desde la sumaria caracterización de las poéticas que asistían a los procesos de creación de nuestro estudiantado en la última década. Desfilaron, en rápida sucesión de imágenes y con sucintas referencias, los proyectos grupales de Galería DUPP, el Colectivo Enema y el Departamento de Intervenciones Públicas (DIP). Cada uno de los participantes del panel, integrantes de algún modo de aquellas experiencias, o valorándolas desde la distancia, expuso sus particularidades distintivas, si bien identificadas todas por el predominio de lo performático.

El esquema referencial operativo (ECRO), siguiendo a Pichon-Riviere, fue en el caso de la Galería DUPP el concepto de galería, de espacio exhibitivo y los modos de problematizarlo. Para el caso del Colectivo Enema se valoraron sus tres vertientes de realización y proyección social: una revista, registros en videos (los denominados Notinemas) y los performances (constituidos como estrategia simbólica de reapropiación de performances clásicos de la historia contemporánea del arte, la cual era al mismo tiempo una operatoria de aprendizaje. Asimismo DIP se construía como experiencia en la cual cada estudiante/artista aportaba un ejercicio al programa (programa en proceso), desde modos no convencionales de simbolización y agenciamiento del espacio público, y con referentes teóricos de variado origen: la psicología ecológica, el psicodrama, la proxemia, el constructivismo radical, la teoría lewiniana del campo, la psicología de la vida cotidiana, entre otros (Cabrera, 2010).

Luego en rápida sucesión de imágenes argumentamos un resurgir de la pintura desde las neo-apropiaciones, atravesando la figuración y los expresionismos y en menor medida hacia los conceptualismos y post-conceptualismos, algo que ha ido cobrando cada vez más protagonismo en los últimos años. De igual modo, se ilustraba el reconocimiento a una práctica fotográfica desde lo conceptual y las prosaicas, a la par que 
mixturadas derivaciones estéticas de los new media y los recursos digitales con todas sus variantes audiovisuales.

Desde tales visualizaciones y experiencias se hacían evidentes o manifiestos, por un lado, una marcada tendencia a desmarcarse de la institución arte, una vocación de re-situación y deslocalización del arte en los imaginarios simbólicos de la contemporaneidad cultural y social, con la revelación de nuevas tendencias hacia lo público y de sus ámbitos de socialización y, por otro lado, un revisitar los predios institucionales del arte desde un imaginario más centrado en las virtualidades del discurso gestáltico o los objetualismos.

Esta necesaria confluencia de espacios académicos y discursos simbólicos abiertos totalmente hacia lo social develaba, para el caso de la práctica artística cubana, una creciente presencia de lo transdisciplinario, un inusitado tránsito hacia los límites porosos entre las disciplinas, y una vecindad contagiosa con lo prosaico. En consecuencia el panel como resultante de la práctica del diplomado acotaba una aguzada necesidad de conocimientos instrumentales y, por lo mismo, concebido desde una articulada díada de lo teórico y lo práctico, donde quedaron superadas la acostumbrada separación de las teorizaciones de un lado y los talleres del otro.

En todo lo apuntado latió, además, seminalmente sin que fuese expuesto explícitamente por ninguno de los ponentes la experiencia imborrable de un grupo teatral que durante más de una década contagió el espacio académico de la Facultad con su obrar: "El Ciervo Encantado"- precisamente el panel se desenvolvió en ese mismo espacio físico otrora ocupado por la magia de aquel grupo. Casi la totalidad de los protagonistas del diplomado había vivido intensos momentos de reflexión estética con las originales e inclasificables obras de este grupo de creación, sumido en la hondura ilimitada de lo imaginal. Ese teatro nacía orgánicamente del entramado experimental del gesto, la acción corporal y la dimensión visual toda del actor; el cuerpo de los actores siempre rendía el principal parlamento, en tanto la voz se proyectaba como una incantación, como un orgánico sonoro más allá de la palabra. Esa frontera borrosa que nos brindó "El Ciervo" volvió a vibrar en el espacio de desarrollo de nuestro panel como un argumento más no declarado, que sabíamos había abrigado seminalmente la experiencia expuesta.

Con el concurso de la antropología visual, la teoría de los campos, la microsociología, la prosaica, la epistemología (el constructivismo radical), lo psicodramático, la investigación en las prácticas simbólicas, se rebasaban las fronteras, se indisciplinaba la mirada y con ello se dibujaba un recorrido que transcurrió desde las prácticas hacia las indisciplinas o desde éstas hacia las prácticas, y desde los procesos y sus asimilaciones recursivas.

Sin tener que penetrar tal conjunto de saberes, el maestro de escuela de hoy abierto sensiblemente a las poco usuales propuestas del activismo artístico de nuestro tiempo, no podría preguntarse: ¿Acaso no podemos y debemos pensar instalacionismo y performance con los niños, dirigidos a su manera de relacionarse entre sí y con su medio? ¿No sería obligado hacerlos pensar su ambiente de un modo distinto a cómo está hecho y no circunscribir la acción educativa en arte centrada en la pintura, en la escultura o en un 
hacer plástico infantil que a eso se remite, sin comprender que el propio accionar de los niños supera en acto lo visual a secas y se convierte en todo un hecho de dramatización de insospechadas derivaciones expresivas?

He aquí preguntas que indisciplinan la mirada, que inician la aventura de las preguntas y de los cuestionamientos y saltan el muro de lo acostumbrado, el mismo que presentamos como extenso epílogo de esta conferencia con la tesina El Aula Oscura del diplomado ya referido.

\section{Referencias bibliográficas:}

Barbosa, Ana Mae (2012) A imagen no ensino da arte. Editora Perspectiva, São Paulo.

Cabrera Salort, Ramón (2010) Freire y Pichon Riviére en los cauces del ISA, en: Indagaciones sobre arte y educación. Editorial Adagio, La Habana.

Colectivo de autores (2011) El aula oscura. Tesina. Instituto Superior de Arte, La Habana.

Debray, Regis (1994) Vida y muerte de la imagen. Historia de la mirada en Occidente. Paidós, Barcelona.

Martín Barbero, Jesús (2003) "Saberes hoy: diseminaciones, competencias y transversalidades”, en: Revista Iberoamericana de educación. No. 32, pp. 17 - 34.

Martí, José (1985) Nueva exhibición de los pintores impresionistas, en: Roberto Fernández Retamar (Comp.) Ensayos sobre Arte y Literatura. Letras Cubanas, La Habana.

Roumá, George (1919) El Lenguaje Gráfico del Niño. La Propagandista, La Habana.

Sábato, Ernesto (2011) Uno y el Universo. Seix Barral, Buenos Aires.

Sanguily, Manuel (1988) La múltiple voz de Manuel Sanguily. Editorial de Ciencias Sociales, La Habana.

Taine, Hipólito (1994) Filosofía del Arte. Editorial Porrúa, México.

Watzlawick, Paul et alt. (1998) El ojo del observador. Editorial Gedisa, Barcelona. 